American J. of Engineering and Applied Sciences 2 (1):194-201, 2009

ISSN 1941-7020

(C) 2009 Science Publications

\title{
Liquefaction Susceptibility in the Northern Provinces of Thailand
}

\author{
${ }^{1}$ Supot Teachavorasinskun, ${ }^{2}$ Pichai Pattararattanakul and ${ }^{2}$ Pulpong Pongvithayapranu \\ ${ }^{1}$ Department of Civil Engineering, Faculty of Engineering, \\ Chulalongkorn University, Phayathai Rd., Pathumwan, Bangkok 10330, Thailand \\ ${ }^{2}$ Department of Civil Engineering, Faculty of Engineering, \\ Chulalongkorn University, Phayathai Rd., Pathumwan, Bangkok, Thailand
}

\begin{abstract}
Problem statement: There are quite a few active faults recently found in the western and northern parts of Thailand, which could possibly induce earthquakes of magnitude $\left(\mathrm{M}_{\mathrm{L}}\right)$ of 5.5-6.5. Although seismic design code has been enforced in the area since 1980, the fundamental knowledge on dynamic soil behavior has not been extensively attained. Approach: Collection of existing borehole information in the targeted areas to form a typical subsoil profile. This borehole information, together with analytical result obtained from logistic regression based on worldwide liquefaction database was used to conduct an effective stress analysis. Result: Literature reviews of the existing boreholes from the two largest provinces in the north, Chiang-Mai and Chiang-Rai, revealed that the areas were underlain by layers of loose to medium dense sand found at shallow depths. The corrected SPT Nvalue of those sand layers varies in the range of 5-20. A simple tool correlating the liquefaction probability, which correlated excess pore water pressure and peak ground acceleration, was proposed for the studied areas. Conclusion: The proposed correlation provided preliminary tool to evaluate risk of the shallow foundation from partial liquefaction in the two northern provinces of Thailand.
\end{abstract}

Key words: Liquefaction, Seismic risk, Earthquakes

\section{INTRODUCTION}

Not until recently that Thailand becomes aware of the threats from earthquakes. There are quite a few moderate earthquakes being felt (Table 1) in Thailand. Epicenters of those recent medium earthquakes were located in the northern and western parts of the country. Warnitchai and Lisantono ${ }^{[1]}$ formulated a database containing instrumental data of earthquakes from 19101989 within the regions bounded by latitudes $5^{\circ} \mathrm{N}$ to $25^{\circ} \mathrm{N}$ and longitudes $90^{\circ} \mathrm{E}$ to $110^{\circ} \mathrm{E}$. They indicated that earthquakes of magnitude $\left(\mathrm{M}_{\mathrm{L}}\right)$ of 6.5 with maximum ground acceleration of $0.2 \mathrm{~g}$ may occur in the northern and western parts of Thailand (Fig. 1). In the northern parts of Thailand, especially the two largest provinces, Chiang-Mai and Chiang-Rai, are generally underlain by layers of loose to medium dense sands at shallow depths (2-8 $\mathrm{m}$ from ground surface) as schematically shown in Fig. 2. Its existence initially infers certain levels of liquefaction risk. This has been further confirmed by evidence showing trace of liquefaction (Fig. 3) found from a trench exploration in the area.
Table 1: Examples of recent earthquakes felt in Thailand

\begin{tabular}{|c|c|c|c|}
\hline Date & Magnitude & Center & Were Felt at \\
\hline April 22, 1983 & 5.9 & $\begin{array}{l}\text { Kanchanaburi, } \\
\text { Thailand }\end{array}$ & $\begin{array}{l}\text { Bangkok, Western } \\
\text { and northern parts }\end{array}$ \\
\hline $\begin{array}{l}\text { November } 6 \text {, } \\
1988\end{array}$ & 7.3 & $\begin{array}{l}\text { Southern of } \\
\text { China }(1,000 \\
\text { km from } \\
\text { Bangkok) }\end{array}$ & $\begin{array}{l}\text { Bangkok, Western } \\
\text { and northern parts }\end{array}$ \\
\hline $\begin{array}{l}\text { September } 29 \text { - } \\
\text { October } 1 \text {, } \\
1989\end{array}$ & $\begin{array}{l}5.3-5.4 \\
\text { Several } \\
\text { quakes }\end{array}$ & Western part & $\begin{array}{l}\text { Bangkok, Western } \\
\text { and northern parts }\end{array}$ \\
\hline $\begin{array}{l}\text { September 11, } \\
1994\end{array}$ & 5.5 & $\begin{array}{l}\text { Phan District } \\
\text { (Northern part) }\end{array}$ & Northern parts \\
\hline $\begin{array}{l}\text { January 22, } \\
2003\end{array}$ & 7.5 & $\begin{array}{l}\text { Sumatra Island } \\
(1,000 \mathrm{~km} \\
\text { from Bangkok) }\end{array}$ & Bangkok \\
\hline $\begin{array}{l}\text { September 22, } \\
2003\end{array}$ & 6.6 & $\begin{array}{l}\text { Burma }(850 \mathrm{~km} \\
\text { from Bangkok })\end{array}$ & $\begin{array}{l}\text { Bangkok and } \\
\text { and northern parts }\end{array}$ \\
\hline
\end{tabular}

Although full initialization of liquefaction may not be the case, partial development of excess pore water pressure might cause damages to 2-3 stories housing which is normally built on shallow foundation or short piles. In the present study, a preliminary study to explore the liquefaction susceptibility of the studied areas was initiated. Integration among field parameters,

Corresponding Author: Supot Teachavorasinskun, Department of Civil Engineering, Faculty of Engineering, Chulalongkorn University, Phayathai Rd., Pathumwan, Bangkok 10330, Thailand 


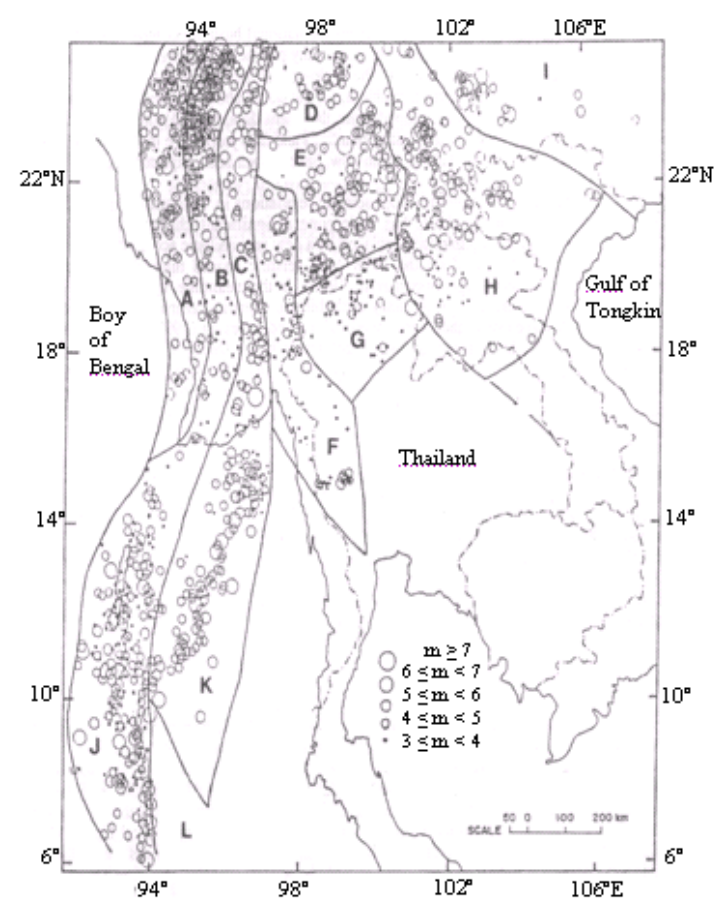

Fig. 1: Seismic source zones in Thailand and vicinity (Warnitchai and Lisantono, ${ }^{[1]}$ )

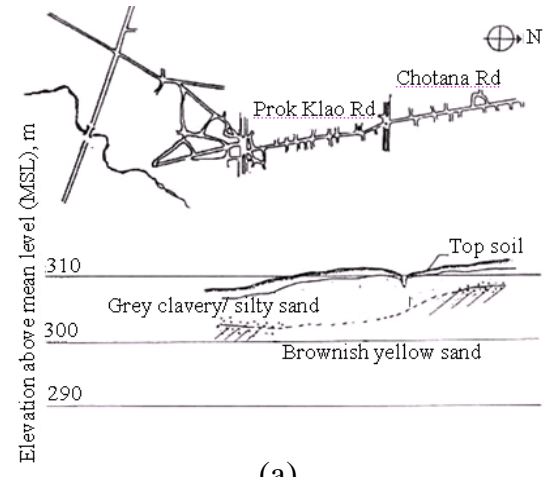

(a)

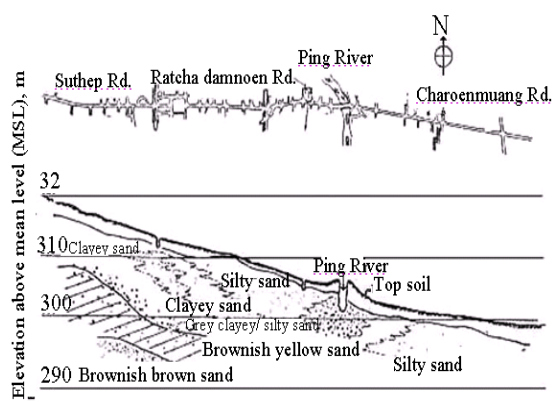

(b)

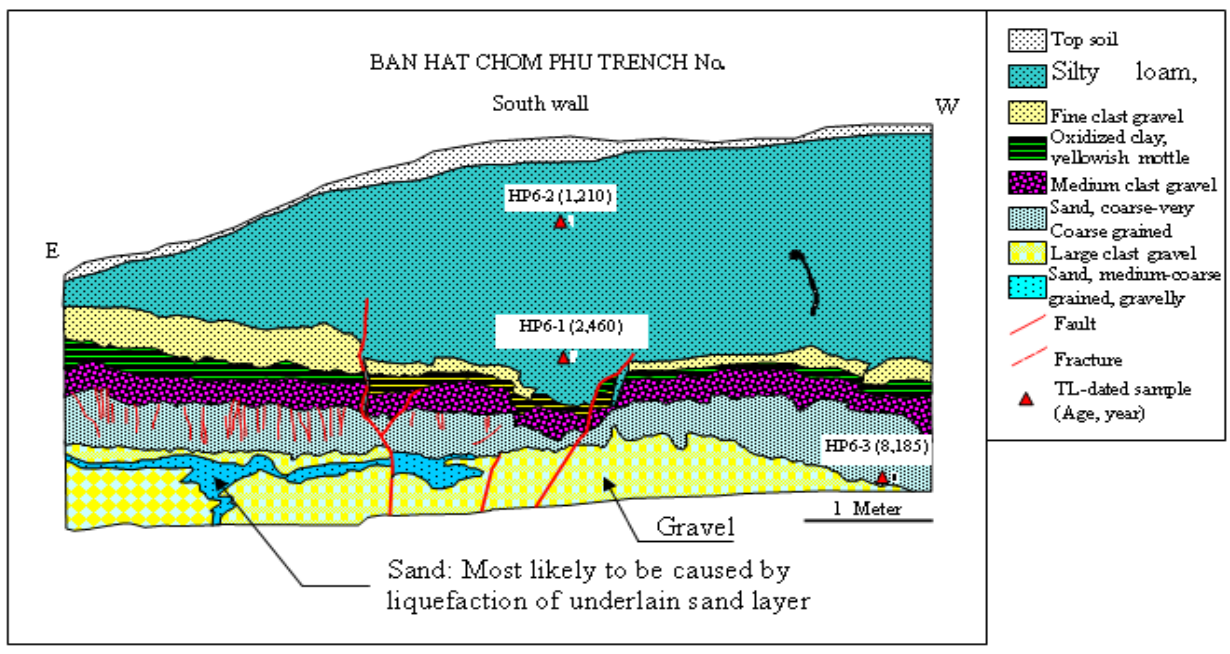

Fig. 3: Evidence of indicating the occurrence of liquefaction the northern area of Thailand

probabilistic study and dynamic analytical results is used as a primary tool for detail evaluation.

\section{MATERIALS AND METHODS}

Fig. 4 shows the general methodology adopted in the present study. To follow the procedure, three main components listed below were to be integrated through the logistic and effective stress analysis to form a general guideline for indicating liquefaction potential in the studied area. Those three main components are;

- Subsurface information: Around 50 existing boring logs were collected from each province. Examples of 
Am. J. Engg. \& Applied Sci., 2 (1):194-201, 2009

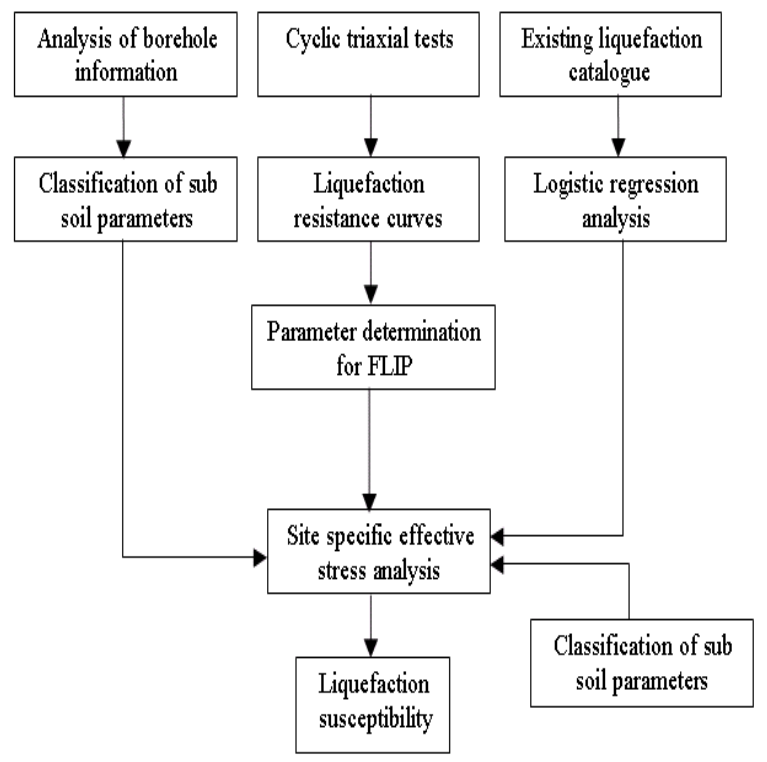

Fig. 4: General methodology adopted in the present study

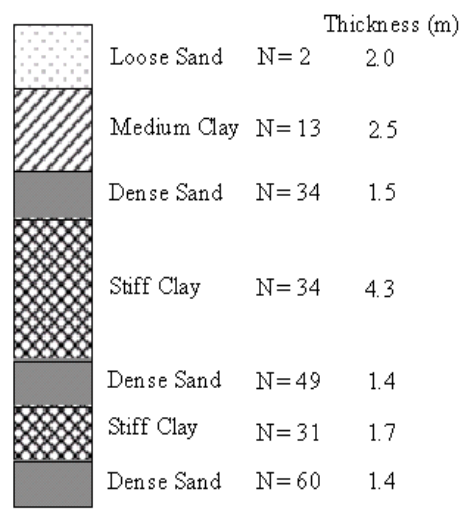

(a)

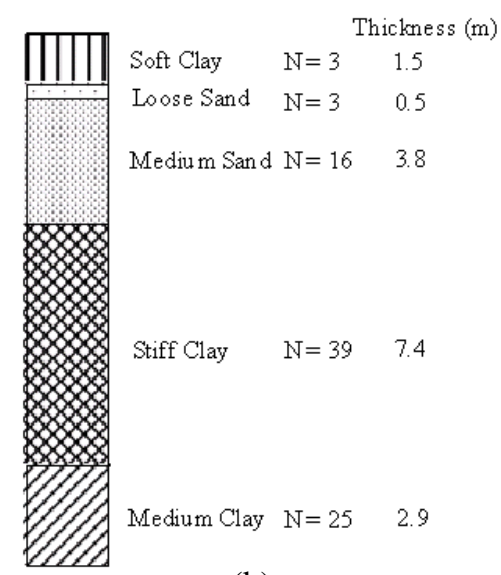

(b)

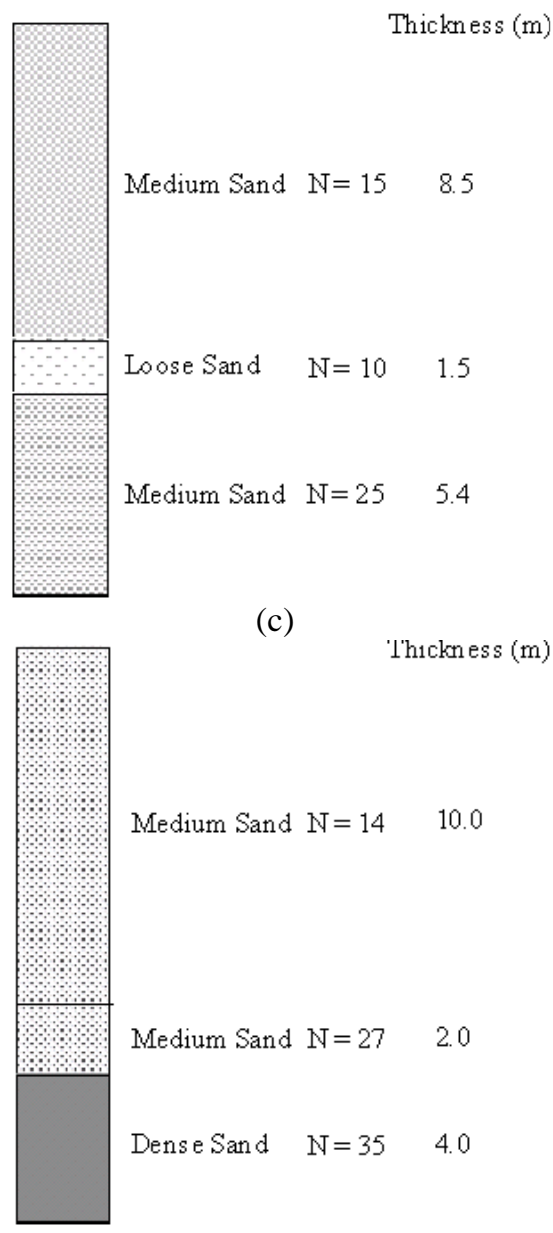

(d)

Fig. 5:Examples of the soil profiles and soil properties collected from Chiang-Mai (a): CMI BH1 (b): CMI BH2 (c): CM2 BH1 (d): CM2BH2

the boring logs are shown in Fig. 5 and 6. The subsoils in both provinces are subject to wide variation. Nevertheless, layers of loose to medium dense sands are found at depths of 2-8 $\mathrm{m}$ in most of the area. The average diameter, $\mathrm{D}_{50}$, of sands varies in the range of $0.2-1.5 \mathrm{~mm}$.

- Laboratory determination of liquefaction resistance. Cyclic triaxial tests determining the liquefaction resistance of were conducted using typical sand samples to obtain some effective stress parameters required in the effective stress analysis ${ }^{[2]}$.

- Existing liquefaction database ${ }^{[3]}$. Since there is no liquefaction database existing for Thailand, the worldwide liquefaction database is used as a 


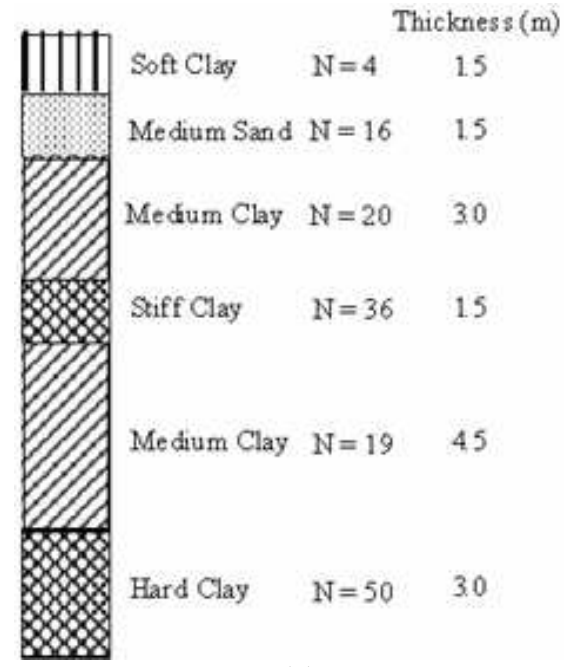

(a)

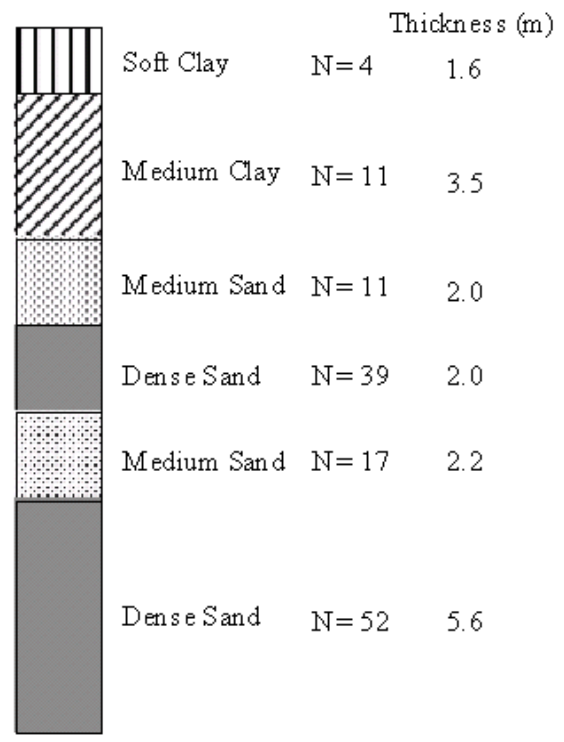

(c)

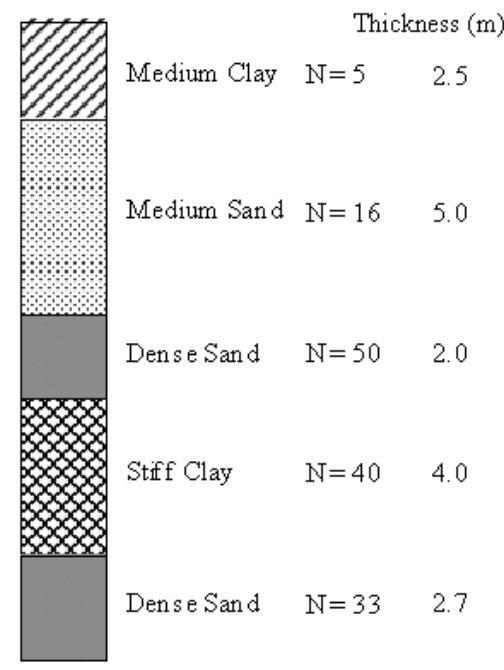

(b)

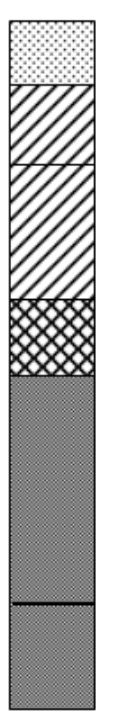

(d)

Fig. 6: Examples of the soil profiles and soil properties collected from Chiang-Rai (a): CR1BH1 (b): CR2BH2 (c): CR3BH1 (d): CR3BH2

reference for determination of other related parameters

Logistic model for evaluation of liquefaction potential: Liquefaction occurs primarily in loose to medium dense saturated sands found at shallow depth. Its occurrence is a function of soil type, relative density, age, amount of Clay Fraction $\mathrm{CF}$, and intensity and duration of the earthquake motion ${ }^{[4]}$. In the past decades, several methods have been proposed to evaluate earthquake liquefaction potential.
These methods range from purely empirical to highly analytical and require various degrees of laboratory and/or in situ testing. The most common approach is to use a deterministic chart expressing the relationship between the corrected SPT N-value and the Cyclic Stress Ratio (CSR). A deterministic line is subjectively drawn to separate events of liquefaction phenomena Juang et al. ${ }^{[5]}$ applied the logistic regression model to create probability function of liquefaction events. The logistic regression is considered more appropriate for 
events with only two occurrence patterns, i.e., liquefaction or non-liquefaction. In the present study, the liquefaction database complied by Liao et al. ${ }^{[3]}$, which composes of 278 case studies was used as reference for conducting the logistic regression analysis. Among the 278 reported cases, 120 events are from Japan, 100 events from California, 20 events from China, and 38 events from other locations around the world.

Each event in the database is represented through a binary variable $\mathrm{Y}$ which indicates whether liquefaction does occur $(\mathrm{Y}=1)$ or does not occur $(\mathrm{Y}=0)$ and a vector expressing the physical variables, $\mathrm{X}=\left[\mathrm{X}_{1}, \mathrm{X}_{2}, \ldots, \mathrm{X}_{\mathrm{m}}\right]^{\mathrm{T}}$. An observation (event) is then written in a short form as (Y,X). Compilation of $n$ events obtained from the database enables to define the liquefaction probability function $\left(\mathrm{P}_{\mathrm{L}}\right)$ as;

$\ln \left(\frac{\mathrm{P}_{\mathrm{L}}}{1-\mathrm{P}_{\mathrm{L}}}\right)=\beta_{0}+\beta_{1} \mathrm{X}_{1}+\ldots+\beta_{\mathrm{m}} \mathrm{X}_{\mathrm{m}}$

Where: $\mathrm{P}_{\mathrm{L}}=$ The probability that liquefaction will occur and $\beta_{\mathrm{i}}=$ A regression constant.

\section{RESULTS AND DISCUSSION}

The most common set of physical variables adopted in several liquefaction studies is the Cyclic Stress Ratio (CSR) and the corrected SPT resistance. The following probabilistic equations provide the best fit to the database.

For earthquake magnitude of 7.5:

$$
\ln \left(\frac{\mathrm{P}_{\mathrm{L}}}{1-\mathrm{P}_{\mathrm{L}}}\right)=9.119-0.243\left(\mathrm{~N}_{1}\right)_{60}+3.458 \ln \left(\mathrm{CSR}_{7.5}\right)
$$

For earthquake magnitude of 5.5:

$$
\ln \left(\frac{\mathrm{P}_{\mathrm{L}}}{1-\mathrm{P}_{\mathrm{L}}}\right)=6.354-0.242\left(\mathrm{~N}_{1}\right)_{60}+3.450 \ln \left(\mathrm{CSR}_{5.5}\right)
$$

Where;

$$
\left(\mathrm{N}_{1}\right)_{60}
$$

$\mathrm{CSR}_{7.5}=$ The cyclic stress ratio generated at the site normalized to a magnitude of 7.5

$\mathrm{CSR}_{5.5}=$ The cyclic stress ratio generated at the site normalized to a magnitude of 5.5

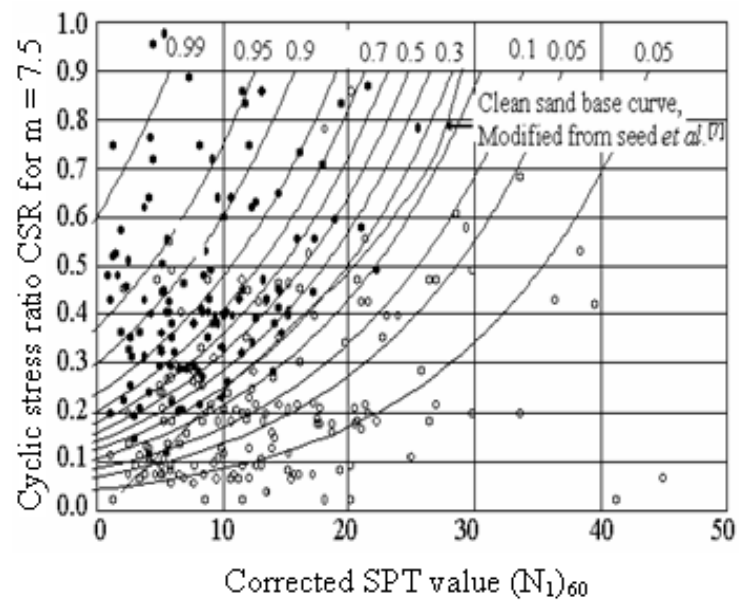

Fig. 7: Contours of equal probability of liquefaction $\left(\mathrm{P}_{\mathrm{L}}\right)$ for magnitude, $\mathrm{M}=7.5$

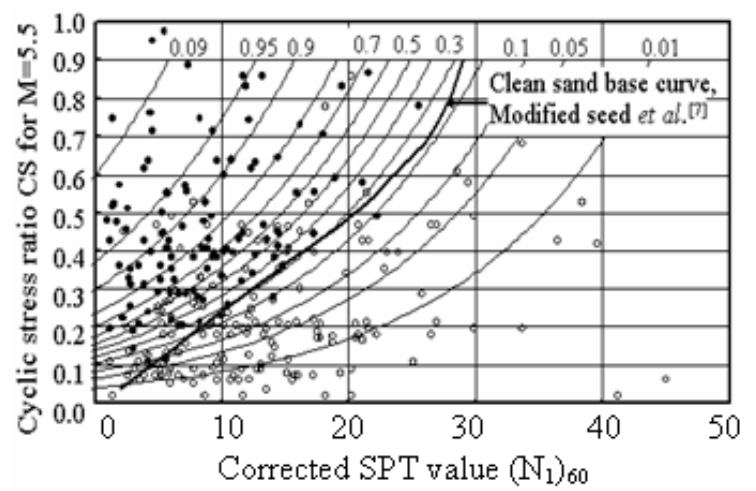

Fig. 8: Contours of equal probability of liquefaction $\left(\mathrm{P}_{\mathrm{L}}\right)$ for magnitude, $\mathrm{M}=5.5$

Fig. 7 and 8 show the set of probability curves defined by Eq. 2 and 3, together with the deterministic criteria defined by Seed et al. ${ }^{[6]}$ The correlation of regression for Eq. 2 and 3 is 0.637. The success rate in classification of liquefaction from both equations is greater than $80 \%$ for both liquefied and non-liquefied cases. It can be seen that the probabilistic line at $\mathrm{P}_{\mathrm{L}}=$ $30 \%$ well traces the deterministic criteria proposed by Seed et al. ${ }^{[6]}$.

Since Chiang-Mai and Chiang-Rai are located in the moderate seismic zone which probable causes earthquake magnitude $\left(\mathrm{M}_{\mathrm{L}}\right)$ of 5-6 (Fig. 1), Eq. 3 is therefore more appropriate as the probability correlation. The factors of safety computed following Seed et $a l^{[7]}$ at various values of $\mathrm{P}_{\mathrm{L}}$ can then be obtained (Table 2). Based on this simplification, at $\mathrm{P}_{\mathrm{L}}$ of $5 \%$, 
Am. J. Engg. \& Applied Sci., 2 (1):194-201, 2009

Table 2: Summary of the estimated values of factor of safety based on the procedure proposed by Seed et al. ${ }^{[7]}$

\begin{tabular}{|c|c|c|c|c|c|c|c|}
\hline \multicolumn{4}{|c|}{ Chiang-Mai } & \multirow{3}{*}{$\begin{array}{l}\text { Site } \\
\% \text { no. }\end{array}$} & \multicolumn{3}{|c|}{ Chiang-Rai } \\
\hline \multirow{2}{*}{$\begin{array}{l}\text { Site } \\
\text { no. }\end{array}$} & \multicolumn{3}{|c|}{ Factor of Safety } & & \multicolumn{3}{|c|}{ Factor of Safety } \\
\hline & $\mathrm{P}_{\mathrm{L}}=5 \%$ & $P_{L}=10 \%$ & $\mathrm{P}_{\mathrm{L}}=30 \%$ & & $\mathrm{P}_{\mathrm{L}}=5 \%$ & $\mathrm{P}_{\mathrm{L}}=10 \%$ & $P_{L}=30 \%$ \\
\hline 1 & 0.51 & 0.64 & 0.95 & 1 & 2.74 & 3.40 & 5.03 \\
\hline 2 & 0.51 & 0.63 & 0.94 & 2 & 1.39 & 1.72 & 2.55 \\
\hline 3 & 0.66 & 0.82 & 1.21 & 3 & 2.01 & 2.50 & 3.70 \\
\hline 4 & 1.26 & 1.56 & 2.31 & 4 & 0.84 & 1.03 & 1.53 \\
\hline 5 & 1.68 & 2.08 & 3.08 & 5 & 0.36 & 0.45 & 0.67 \\
\hline 6 & 0.57 & 0.70 & 1.03 & 6 & 0.60 & 0.74 & 1.10 \\
\hline 7 & 1.23 & 1.52 & 2.25 & 7 & 1.00 & 1.24 & 1.83 \\
\hline 8 & 0.83 & 1.02 & 1.51 & 8 & 0.99 & 1.23 & 1.82 \\
\hline 9 & 0.64 & 0.79 & 1.17 & 9 & 1.26 & 1.57 & 2.32 \\
\hline 10 & 0.89 & 1.10 & 1.63 & 10 & 0.77 & 0.96 & 1.42 \\
\hline 11 & 1.23 & 1.52 & 2.25 & 11 & 0.49 & 0.61 & 0.90 \\
\hline 12 & 1.80 & 2.23 & 3.30 & 12 & 1.05 & 1.30 & 1.92 \\
\hline 13 & 1.66 & 2.06 & 3.06 & 13 & 0.86 & 1.06 & 1.57 \\
\hline 14 & 0.69 & 0.87 & 1.27 & 14 & 0.50 & 0.63 & 0.93 \\
\hline 15 & 0.87 & 1.08 & 1.60 & 15 & 1.05 & 1.30 & 1.93 \\
\hline 16 & 0.50 & 0.62 & 0.92 & 16 & 10.24 & 12.72 & 18.81 \\
\hline 17 & 0.52 & 0.65 & 0.96 & 17 & 0.78 & 0.98 & 1.44 \\
\hline 18 & 0.58 & 0.71 & 1.06 & & & & \\
\hline 19 & 1.42 & 1.77 & 2.61 & & & & \\
\hline 20 & 0.81 & 1.00 & 1.48 & & & & \\
\hline 21 & 1.09 & 1.35 & 1.99 & & & & \\
\hline 22 & 1.03 & 1.29 & 1.91 & & & & \\
\hline 23 & 1.95 & 2.43 & 3.59 & & & & \\
\hline 24 & 0.85 & 1.05 & 1.55 & & & & \\
\hline 25 & 0.65 & 0.82 & 1.20 & & & & \\
\hline 26 & 2.04 & 2.53 & 3.74 & & & & \\
\hline 27 & 1.06 & 1.31 & 1.93 & & & & \\
\hline 28 & 0.45 & 0.56 & 0.83 & & & & \\
\hline 29 & 0.86 & 1.07 & 1.58 & & & & \\
\hline
\end{tabular}

there are more than $80 \%$ of the sandy sites being subject to a certain level of liquefaction susceptibility.

Analysis for estimation of excess pore water pressure: The analytical result clearly indicated certain levels of liquefaction risk in the studied area. It is therefore necessary to somewhat quantify the risk. The most common and direct method is to evaluate the possible amount of excess pore water pressure, which requires the effective stress analysis. The computer program called "FLIP (Finite Element Analysis Of Liquefaction Program)" developed by Iai et al. ${ }^{[2]}$ was used.

The effective stress model used in "FLIP" requires ten parameters which specify elastic properties, plastic shear behavior and dilatancy (Table 3). The elastic properties were computed based on the correlations given in Table 4, while the others were determined from trial the analytical result to the undrained cyclic triaxial tests (Fig. 9). Due to the lack of strong motion record in Thailand, the recorded waveform of El-Centro
Table 3: Model parameters (Iai et al. ${ }^{[2]}$ )

\begin{tabular}{|c|c|c|c|}
\hline Parameter & Value & Type of Mechanism & Kind of the Parameter \\
\hline $\mathrm{K}_{\mathrm{ma}}$ & See Table 4 & Elastic volumetric & Rebound modulus \\
\hline $\mathrm{G}_{\mathrm{ma}}$ & See Table 4 & Elastic shear & Shear modulus \\
\hline$\varphi_{\mathrm{f}}$ & $15^{\circ}$ & Plastic shear & Shear resistance angle \\
\hline$\varphi_{\mathrm{p}}$ & See Table 4 & Plastic dilatancy & Phase transformation \\
\hline $\mathrm{H}_{\mathrm{m}}$ & See Table 4 & Plastic shear & $\begin{array}{l}\text { angle } \\
\text { Hysteretic damping } \\
\text { factor at large shear } \\
\text { strain level }\end{array}$ \\
\hline $\mathrm{p}_{1}$ & $0.6-0.7$ & Plastic dilatancy & $\begin{array}{l}\text { Initial phase of } \\
\text { dilatancy }\end{array}$ \\
\hline $\mathrm{p}_{2}$ & $0.4-0.8$ & Plastic dilatancy & $\begin{array}{l}\text { Final phase of } \\
\text { dilatancy }\end{array}$ \\
\hline $\mathrm{w}_{1}$ & $9.5-38.5$ & Plastic dilatancy & Overall dilatancy \\
\hline $\mathrm{s}_{1}$ & 0.005 & Plastic dilatancy & $\begin{array}{l}\text { Ultimate limit of } \\
\text { dilatancy }\end{array}$ \\
\hline$c_{1}$ & 1.0 & Plastic dilatancy & Threshold limit \\
\hline
\end{tabular}

Table 4: Fundamental soil properties used in analysis

\begin{tabular}{|c|c|c|}
\hline Soil type & Formulation & Reference \\
\hline Soft clay & $\begin{array}{l}\mathrm{V}_{\mathrm{s}}=68.7 . \mathrm{S}_{\mathrm{u}}^{0.475}\left(\mathrm{~m} \mathrm{sec}^{-1}\right) \\
\mathrm{S}_{\mathrm{u}}=\mathrm{t} \mathrm{m}^{-2}\end{array}$ & Dickenson $^{[8]}$ \\
\hline Medium & $\mathrm{V}_{\mathrm{s}}=96.926 . \mathrm{N}^{0.314}\left(\mathrm{~m} \mathrm{sec}^{-1}\right)$ & Imai and \\
\hline to stiff clay & $\mathrm{N}_{\mathrm{c}}=$ Uncorrected SPT N-value & Tonouchi $^{[9]}$ \\
\hline Silty sand & $\begin{array}{l}\mathrm{V}_{\mathrm{s}}=56.388 . \mathrm{N}_{\mathrm{c}}^{0.5}\left(\mathrm{~m} \mathrm{sec}^{-1}\right) \\
\mathrm{N}_{\mathrm{c}}=\text { Corrected SPT N-value }\end{array}$ & Seed et $_{\text {al. }}{ }^{[10]}$ \\
\hline Sandy soil & $\begin{aligned} \mathrm{V}_{\mathrm{s}} & =100.584 . \mathrm{N}_{\mathrm{c}}^{0.29}\left(\mathrm{~m} \mathrm{sec}^{-1}\right) \\
\mathrm{N}_{\mathrm{c}} & =\text { Corrected SPT N-value }\end{aligned}$ & $\begin{array}{l}\text { Sykora and } \\
\text { Stokoe }^{[11]}\end{array}$ \\
\hline $\begin{array}{l}\text { Strain dependent } \\
\text { characteristics of } \\
\text { shear modulus } \\
\text { and damping ratio }\end{array}$ & - & $\begin{array}{l}\text { Vucetic and } \\
\text { Dobry }\end{array}$ \\
\hline $\mathrm{K}_{\mathrm{ma}}$ & $\mathrm{K}_{\mathrm{ma}}=\frac{2 \mathrm{G}(1+v)}{3(1-2 v)}(\mathrm{kPa})$ & - \\
\hline \multirow{3}{*}{$\mathrm{G}_{\mathrm{ma}}$} & $\mathrm{U}=$ Passion's ratio $=0.33$ & \\
\hline & $\mathrm{G}_{\mathrm{ma}}=\rho \cdot \mathrm{V}_{\mathrm{s}}^{2}(\mathrm{kPa})$ & \\
\hline & $\mathrm{P}=$ soil density & - \\
\hline$\varphi_{\mathrm{p}}$ & 28 degrees & Ishihara $^{[13]}$ \\
\hline $\mathrm{H}_{\mathrm{m}}$ & 0.30 & Ishihara $^{[13]}$ \\
\hline
\end{tabular}

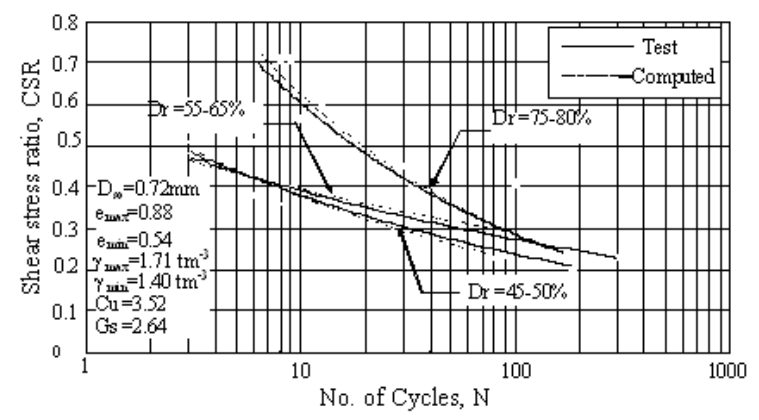

Fig. 9: Test and computed liquefaction resistance curves 
will be used for the analysis. The analytical procedure of a site was conducted as following;

- Determine the minimum value of SPT of the computed site,

- Select cyclic stress ratio (CSR) and $\mathrm{P}_{\mathrm{L}}$ from the probability curves (Fig. 8),

- Determine the maximum ground surface acceleration $\left(a_{\max }\right)$ from the simplified equation proposed by Seed et al. ${ }^{[7]}$ as:

$$
\operatorname{CSR}=\frac{\tau_{\text {ave }}}{\sigma_{\mathrm{vo}}^{\prime}}=0.65 \frac{\sigma_{\mathrm{vo}}}{\sigma_{\mathrm{vo}}^{\prime}} \cdot \frac{\mathrm{a}_{\max }}{\mathrm{g}} \cdot \mathrm{r}_{\mathrm{d}}
$$

Where:

$\sigma_{\mathrm{vo}}=$ Total overburden pressure on sand layer under consideration

$\sigma_{\mathrm{vo}}^{\prime}=$ Initial effective overburden pressure on sand layer under consideration.

The term $r_{d}$ was calculated following Liao et al. ${ }^{[3]}$ as:

$$
\begin{array}{ll}
\mathrm{r}_{\mathrm{d}}=1.0-0.00765 \mathrm{z} & \text { for } \mathrm{z} \leq 9.15 \mathrm{~m} \\
\mathrm{r}_{\mathrm{d}}=1.174-0.0267 \mathrm{z} & \text { for } 9.15 \mathrm{~m}<\mathrm{z} \leq 23 \mathrm{~m}
\end{array}
$$

- Randomly scale the input maximum base acceleration so that the computed maximum ground acceleration was similar to the prescribed value given by Eq. 4 .

The total of twenty-nine sandy sites within ChiangMai City and seventeen sandy sites within Chiang-Rai City were analysed. Fig. 10 and 11 show the typical analytical results by plotting the maximum excess pore water pressure ratio, $\Delta u / \sigma_{v}^{\prime}$, against the maximum ground acceleration. In case where $\mathrm{P}_{\mathrm{L}}=30 \%$, large values of excess pore water pressure ratio was obtained from most sites. This is not applicable to the area, since $\mathrm{a}_{\max }$ is much greater than $0.2 \mathrm{~g}$ (which is the most likely maximum ground acceleration indicated from the recorded earthquakes). When $\mathrm{P}_{\mathrm{L}}$ was reduced to 5\%, for $a_{\max }<0.2 \mathrm{~g}$ ), the excess pore water pressure ratio in the range of 0.1-0.4 can be observed. The temporary reduction in effective stress can directly decrease the bearing capacity of the sandy soil layers. The shallow foundation or short pile built in the areas should therefore be compensated for this temporary effect. A proper safety margin of about $1 / 0.6(\approx 1.3)$ should be multiplied to the conventional factor of safety.

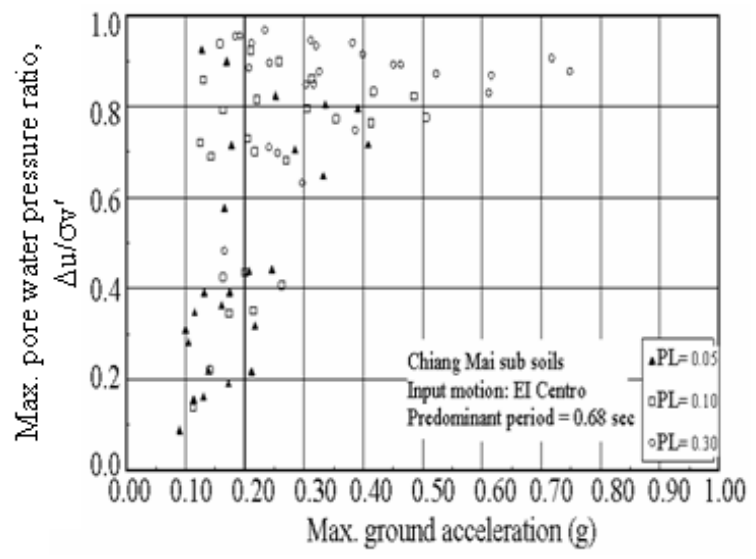

Fig. 10: Relationships between maximum ground acceleration and maximum pore water pressure ratio for Chiang-Rai

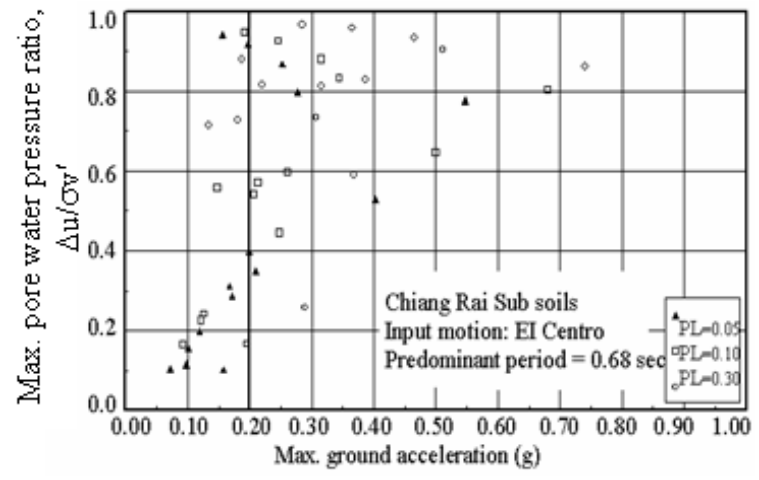

Fig. 11: Relationships between maximum ground acceleration and maximum pore water pressure ratio for Chiang-Rai

\section{CONCLUSION}

The liquefaction probability due to medium earthquakes in the northern parts of Thailand, particularly Chiang-Mai and Chiang-Rai, were studied. Logistic regression model based on worldwide liquefaction database was used to form the probabilistic base correlation between cyclic stress ratio and the SPT resistance. It was found that with $\mathrm{P}_{\mathrm{L}}$ of $5 \%$, there are some sites prone to partial liquefaction with the excess pore water pressure ratio varies in the range of 0.1- 0.4. This may cause discernible damage to the 2-3 stories housing which is general rest on shallow foundation or short piles. The temporary increase in excess pore water pressure should be compensated by providing a proper safety margin. 


\section{ACKNOWLEDGEMENT}

The writers would like to thank Thailand Research Fund (TRF) for providing research fund to the study.

\section{REFERENCES}

1. Warnitchai, P. and A. Lisantono, 1996. Probabilistic seismic risk mapping for Thailand. 11th World Conference on Earthquake Engineering, June 23-28, Acapulco, Mexico, pp: 1258-1265.

2. Iai S., Y. Matsunaga, and T. Kameoka, 1992. Strain space plasticity model for cyclic mobility. Soils $\quad$ Foundations, 32: 1-15. http://ci.nii.ac.jp/naid/110003959883/.

3. Liao, S.S.C., D. Veneziano and R.V. Whitman, 1988. Regression models for evaluating liquefaction probability. J. Geotechnical Eng., 114: 389-411. http://cedb.asce.org/cgi/WWWdisplay.cgi?8801061.

4. Seed, H.B. and I.M. Idriss, 1971. Simplified procedure for evaluating soil liquefaction potential. J. Soil Mechan. Foundat. Div., 97: 1249-1273. http://cedb.asce.org/cgi/WWWdisplay.cgi?7100947.

5. Juang C.H, T. Jiang and R.D. Andrus, 2002. Assessing probability-based methods for liquefaction potential evaluation. J. Geotechni. Geoenviron. $\quad$ Eng., $\quad 128$ : 580-589. http://cedb.asce.org/cgi/WWWdisplay.cgi?0203599.

6. Seed, H.B., K. Tokimatsu, L.F. Harder, and R.M. Chung, 1985. Influence of SPT procedures in soil liquefaction resistance evaluations. J. Geotechni. Eng., 111: 1425-1445.

http://cedb.asce.org/cgi/WWWdisplay.cgi?8503442.
7. Seed, H.B., I.M. Idriss, and I. Arango, 1983. Evaluation of liquefaction potential using field performance data. J. Geotechni. Eng., 109: 458-482. http://cedb.asce.org/cgi/WWWdisplay.cgi?8300283.

8. Dickenson S.E., 1994. Dynamic response of soft and deep cohesive soils during the Loma Prieta earthquake of October 17, 1989. Ph.D. Dissertation, Department of Civil Engineering, University of California, Berkeley, California. http://nisee.berkeley.edu/loma_prieta/stewart.html

9. Imai T. and K. Tonuchi, 1982. Correlation of Nvalue with S-wave velocity and shear modmlasin. Thailand Eng. J Proceedings of 2nd European Symposium on Penetration Testing, May 24-27, Amsterdam, Netherlands, $\quad$ pp: 332-337. http://nisee.berkeley.edu/loma_prieta/stewart.html.

10. Seed, H.B., R.T. Wong, I.M. Idriss and K. Tokimatsu, 1984. Moduli and damping factors for dynamic analyses of cohesionless soils. Report No. UCB/EERC-84/14, Earthquake Engineering Research Center, University of California, Berkeley, California.

11. Sykora, D.W. and K.H. Stokoe, 1983. Correlations of in-situ measurements in sands with shear wave velocity. Geotechical Engineering Report GR 8333, The University of Texas at Austin, Texas.

12. Vucetic, M. and R. Dobry, 1991. Effect of soil plasticity on cyclic response. J. Geotechnical Eng., 117: 89-107. DOI: 10.1061/(ASCE)07339410(1991)117:1(89)).

13. Ishihara, K. 1986. Evaluation of soil properties for use in earthquake response analysis. Geotechnical Modell. Earthquake Eng. Practice, Balkema, 241275.

http://cat.inist.fr/?aModele=afficheN\&cpsidt=8207677. 